\title{
Total saponins from Rhizoma Panacis Majoris inhibit proliferation, induce cell cycle arrest and apoptosis and influence MAPK signalling pathways on the colorectal cancer cell
}

\author{
LU CHANG ${ }^{*}$, RUI ZHOU*, YIHAN HE, MEI MENG, JINHANG HU, YANRU LIU, \\ YALEI PAN, ZHISHU TANG and ZHENGGANG YUE
}

\begin{abstract}
State Key Laboratory of Research and Development of Characteristic Qin Medicine Resources (Cultivation)/Co-construction Collaborative Innovation Center for Chinese Medicine Resources Industrialization by Shaanxi and Education Ministry/Shaanxi Innovative Drug Research Center, School of Pharmacy, Shaanxi University of Chinese Medicine, Xianyang, Shaanxi 712046, P.R. China
\end{abstract}

Received November 20, 2020; Accepted April 20, 2021

DOI: $10.3892 / \mathrm{mmr} .2021 .12181$

\begin{abstract}
Colorectal cancer (CRC) ranks third in incidence and second in mortality among all types of cancer, and due to its insidious onset and lack of early symptoms, it is usually diagnosed at a later stage. Saponins, a class of compounds abundant in plants, have been reported to possess prominent anti-tumour properties. The use of ginsenoside Rg3 in the clinical setting was authorized by the National Medicinal Products Administration of China. In the present study, total saponins from Rhizoma Panacis Majoris (RPMTG) were prepared, and the pharmacological mechanisms underlying the anti-CRC effects of RPMTG were investigated. The effect of RPMTG on the proliferation, cell cycle progression and apoptosis of HCT116 and SW620 cells were detected by MTT, flow cytometry and western blotting assays, and it was demonstrated that RPMTG could inhibit the proliferation of HCT116 and SW620 cells with IC50 values of 315.8 and $355.1 \mu \mathrm{g} / \mathrm{ml}$, respectively, induce cell cycle arrest in the $\mathrm{S}$ and $\mathrm{G0} / \mathrm{G} 1$ phase, and trigger apoptosis by downregulating the expression of the anti-apoptotic proteins Bcl-2, Bcl-xL and induced myeloid leukaemia cell differentiation protein Mcl-1, and increasing the expression of the pro-apoptotic proteins Bax and Bad, cleaved caspased-3 and poly(ADP)-ribose polymerase. These findings suggested that RPMTG induced apoptosis
\end{abstract}

Correspondence to: Dr Yihan He or Dr Zhenggang Yue, State Key Laboratory of Research and Development of Characteristic Qin Medicine Resources (Cultivation)/Co-construction Collaborative Innovation Center for Chinese Medicine Resources Industrialization by Shaanxi and Education Ministry/Shaanxi Innovative Drug Research Center, School of Pharmacy, Shaanxi University of Chinese Medicine, 1 Xixian Avenue, Xianyang, Shaanxi 712046, P.R. China E-mail: annaaid@126.com

E-mail: liuxingjian1981@163.com

*Contributed equally

Key words: RPMTG, colorectal cancer, apoptosis, cell cycle arrest, MAPK signalling pathways through mitochondrial-related pathways. In addition, RPMTG also decreased the expression of phosphorylated (p)-extracellular signal-regulated kinase and increased p-c-Jun N-terminal kinase (p-JNK) and p-p38. Moreover, the effects of RPMTG on cell proliferation and apoptosis were partially reversed when the JNK and p38 mitogen-activated protein kinase (MAPK) pathways were inhibited, indicating that RPMTG triggered apoptosis mainly via regulating JNK and p38 MAPK signalling. Therefore, RPMTG may have potential as an anti-CRC agent, and further evaluations are needed.

\section{Introduction}

Colorectal cancer (CRC) is a type of malignant tumour that arises from the epithelial cells of the mucosal lining of the colon or rectum, and ranks third in incidence and second in mortality among all cancers worldwide, with its occurrence, growth and metastasis being affected by irregular diet, lack of exercise and genetic factors $(1,2)$. It has been predicted that the number of new cases of CRC worldwide will increase to $>2.2$ million by 2030 (2). With the advances in surgical resection, radiotherapy, chemotherapy, adjuvant chemotherapy, receptor-targeted therapy and other therapeutic measures, significant progress has been achieved in the clinical treatment of CRC (3). Surgical resection remains the preferred treatment method for local CRC, whereas the applicability of postoperative chemotherapy is limited by side effects and the development of drug resistance, which may significantly reduce patient compliance and quality of life (4-6).

Herbal medicines and natural products are known sources of anti-tumour drugs, such as paclitaxel derived from the bark of the Pacific yew Taxus brevifolia, camptothecin derived from the root bark of Camptotheca acuminate and podophyllotoxin derived from the rhizome of Diphylleia sinensis (7-9). Saponins, a class of ingredients abundant in plants, have been recognised for their anti-tumour properties, with ginsenosides derived from Panax ginseng (P. ginseng), a species in the Panax genus of the Araliaceae family, considered as the most active components $(10,11)$. Ginsenosides 
include the 20(S)-protopanaxadiol and 20(S)-protopanaxatriol saponins (12). Among the hundreds of compounds included in $P$. ginseng, ginsenoside Rg3 has been authorized for use as a clinical drug by the National Medicinal Products Administration of China (13).

Panax japonicus var. Major is another species in the Panax genus, and its root, named Rhizoma Panacis Majoris, has been found to predominantly contain saponins, polysaccharides and organic acids (14). Previous studies have demonstrated that the decoction of Rhizoma Panacis Majoris can inhibit proliferation and induce apoptosis of human liver cancer SMMC-7721 cells and human promyelocytic leukaemia HL-60 cells, whereas the polysaccharides of Rhizoma Panacis Majoris can inhibit tumour growth and prolong survival in a H22 hepatoma mouse model through enhancing immunity $(15,16)$. However, the effect of saponins from Rhizoma Panacis Majoris on CRC has not been investigated to date.

In the present study, total saponins from Rhizoma Panacis Majoris (RPMTG) were prepared, the effects of RPMTG on the proliferation, cell cycle and apoptosis of HCT116 and SW620 cells were investigated, and the underlying molecular mechanism was elucidated.

\section{Materials and methods}

Plant material. Panax japonicus var. major was collected from the Taibai region of Qinling Mountains in the Shaanxi Province of China, and was identified morphologically and histologically by Professor Wei Wang (TCM Identification Department of Shaanxi University of Chinese Medicine, Xianyang, China). The roots of the plant were processed by the TCM resource laboratory at the Shaanxi University of Chinese Medicine (Xianyang, China) and authenticated as Rhizoma Panacis Majoris, and a voucher specimen (herbarium no. 20180920) has been deposited in the Medicinal Plants Herbarium, Shaanxi University of Chinese Medicine (Xianyang, China).

Preparation of RPMTG. The dried crude materials were extracted with $70 \%$ ethanol three times. After removing the solvent under reduced pressure, the ethanol extract was suspended in $\mathrm{H}_{2} \mathrm{O}$, subjected to macroporous resin (DIAION ${ }^{\circledR}$ HP20 gel, Mitsubishi Gas Chemical Company, Inc.) column chromatography and eluted with a gradient solvent system of ethanol (i.e., 0, 20, 60 and 95\% ethanol) to yield four fractions. The fractions were detected by UV spectrophotometry (UV-2600i; Shimadzu Corporation) and high-performance liquid chromatography-electrospray ionization-tandem mass spectrometry [Agilent 1260 HPLC (Agilent Technologies, Inc.) equipped with QTRAP ${ }^{\circledR} 4500 \mathrm{MS}$ system (SCIEX)]. A SunFire C18 column (150x4.6 mm, $5 \mu \mathrm{m}$; Waters Corporation) was used with $30^{\circ} \mathrm{C}$ column temperature. The mobile phase consisted of $\mathrm{A}\left(\mathrm{H}_{2} \mathrm{O}+0.05 \% \mathrm{HCOOH}\right)$ and $\mathrm{B}\left(\mathrm{CH}_{3} \mathrm{CN}+0.05 \%\right.$ $\mathrm{HCOOH}$ ) using a gradient elution of $0-5 \mathrm{~min}, 10-23 \% \mathrm{~B}$; 5-15 $\mathrm{min}, 23-35 \% \mathrm{~B}$; $15-20 \mathrm{~min}, 35-48 \% \mathrm{~B} ; 20-25 \mathrm{~min}$, $48-96 \% \mathrm{~B} ; 25-28 \mathrm{~min}, 96-10 \% \mathrm{~B} ; 28-30 \mathrm{~min}, 10 \% \mathrm{~B}$. The volume flow was $0.8 \mathrm{ml} / \mathrm{min}$, and the injection volume was $5 \mu \mathrm{l}$.

The $60 \%$ ethanol fraction was identified as the total saponins site with $73.09 \%$ RPMTG content, and 15 saponins were determined as ginsenosides $\mathrm{Rb}_{2}$, Re, Ro, Rd, $\mathrm{Rg}_{1}, \mathrm{Rb}_{3}, \mathrm{Rb}_{1}, \mathrm{Rc}$, $\mathrm{Rh}_{2}, \mathrm{~F} 2, \mathrm{Rg}_{3}$ and $\mathrm{Rf}$, Panax notoginseng saponin $\mathrm{R}_{1}$, Panax zingiberensis saponin $\mathrm{R}_{1}$ and chikusetsusaponin IVa. Finally, RPMTG powder was obtained after freeze-drying and used in mechanistic studies.

Cell culture. The human CRC cell lines HCT116 and SW620 were purchased from The Cell Bank of Type Culture Collection of The Chinese Academy of Sciences. HCT116 and SW620 cells were cultured in Dulbecco's modified Eagle's medium (DMEM; Gibco; Thermo Fisher Scientific, Inc.), supplemented with 10\% FBS (Gibco; Thermo Fisher Scientific, Inc.), $100 \mathrm{U} / \mathrm{ml}$ penicillin and $100 \mu \mathrm{g} / \mathrm{ml}$ streptomycin. The HCT116 $\left(1 \times 10^{4}\right.$ cells/well) and SW620 $\left(2 \times 10^{4}\right.$ cells/well $)$ cells were pretreated with JNK inhibitor (SP600125, $10 \mu \mathrm{M}$; Beyotime Institute of Biotechnology) and p38 inhibitor (SB203580, $10 \mu \mathrm{M}$; Beyotime Institute of Biotechnology) for $2 \mathrm{~h}$, and then treated with $250 \mu \mathrm{g} / \mathrm{ml} \mathrm{RPMTG}$ for $24 \mathrm{~h}$ in a $37^{\circ} \mathrm{C}$ incubator containing $5 \% \mathrm{CO}_{2}$. In subsequent experiments, the effects of RPMTG combined with JNK inhibitors or p38 inhibitors on proliferation and apoptosis were evaluated.

MTT assay. Cell viability was detected by the MTT assay (Sigma-Aldrich; Merck KGaA). HCT116 and SW620 cells were digested, dispersed and inoculated in 96-well plates at a density of $1 \times 10^{4}$ cells/well and $2 \times 10^{4}$ cells/well, respectively. The cells were cultured in complete DMEM and incubated in a $37^{\circ} \mathrm{C}$ incubator containing $5 \% \mathrm{CO}_{2}$. After cells were allowed to proliferate for $24 \mathrm{~h}, \mathrm{RPMTG}$ at different concentrations $(0,100$, $200,250,300,400$ and $500 \mu \mathrm{g} / \mathrm{ml}$ ) was added; after 12 and $24 \mathrm{~h}$, $15 \mu \mathrm{l}$ MTT was added into each well of the blank group and the RPMTG treatment group; after a further $4 \mathrm{~h}, \mathrm{DMSO}$ was added, and the plates were analysed at $490 \mathrm{~nm}$ on a microplate reader (Thermo Fisher Scientific, Inc.). The ratio of cell survival was calculated against that of the untreated CRC cell group.

Cell cycle assay. Cell cycle progression was assessed by flow cytometry (FACSCanto II; BD Biosciences). Cells were treated with different concentrations $(0,100$ and $200 \mu \mathrm{g} / \mathrm{ml})$ of RPMTG for $24 \mathrm{~h}$, washed with PBS, and fixed with absolute ethanol at $-20^{\circ} \mathrm{C}$ overnight. Then, cells were collected, and $100 \mu 1$ RNase A was added to resuspend the cells. Propidium iodide (PI; $400 \mu \mathrm{l}$, $50 \mu \mathrm{g} / \mathrm{ml}$; Beyotime Institute of Biotechnology) was added and allowed to act in the dark for $30 \mathrm{~min}$. The content of PI-labelled DNA in the cells was then quantified by flow cytometry. FlowJo version 10 software (FlowJo LLC) was used for analysis. The experiments were performed three times.

DAPI staining. DAPI staining was used to evaluate the specific morphological changes in the nucleus that induced apoptosis. HCT116 and SW620 cells were seeded into 6-well plates at a density of $1 \times 10^{5}$ cells $/ \mathrm{ml}$ and $2 \times 10^{5}$ cells $/ \mathrm{ml}(2 \mathrm{ml}$ per well), respectively. Cells were treated with different concentrations $(0,100,200$ and $250 \mu \mathrm{g} / \mathrm{ml})$ of RPMTG for $24 \mathrm{~h}$, then washed with PBS, fixed with $4 \%$ paraformaldehyde for $15 \mathrm{~min}$ in a $37^{\circ} \mathrm{C}$ incubator containing $5 \% \mathrm{CO}_{2}$ and stained with $5 \mu \mathrm{g} / \mathrm{ml}$ DAPI (Beyotime Institute of Biotechnology) in the dark for 15 min at room temperature. Finally, cells were examined with an inverted fluorescence microscope (magnification, x20), representative digital images were acquired for analysis. The mean number of nuclear apoptotic cells and cell count of 10 selected fields $\left(500 \times 500\right.$ pixel $\left.^{2}\right)$ in the images were calculated. 

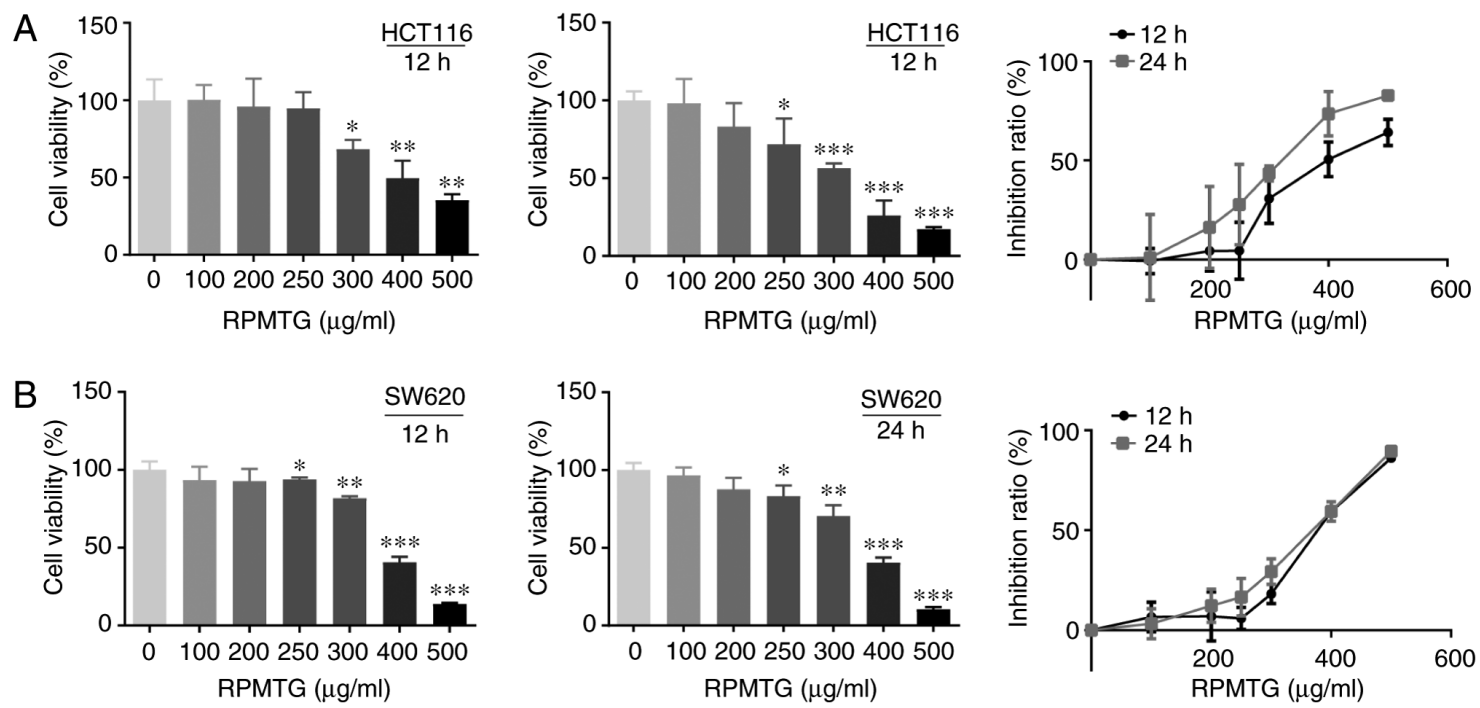

Figure 1. RPMTG inhibits the viability and proliferation of HCT116 and SW620 cells. The (A) HCT116 and (B) SW620 cells were allowed to grow and adhere for $24 \mathrm{~h}$, after which RPMTG $(0,100,200,250,300,400$ and $500 \mu \mathrm{g} / \mathrm{ml})$ was added and cell proliferation was determined at 12 and $24 \mathrm{~h}$. Data are expressed as the mean \pm SD from three independent experiments. ${ }^{*} \mathrm{P}<0.05,{ }^{* *} \mathrm{P}<0.01$ and ${ }^{* * * *} \mathrm{P}<0.001$ vs. control group. RPMTG, total saponins from Rhizoma Panacis Majoris.

Apoptosis assay. Early and late (lower and top right corner of the flow dot plot, respectively) stage apoptosis were detected by the Annexin V/PI detection kit (Absin Bioscience, Inc.) according to the manufacturer's instructions. HCT116 and SW620 cells were treated with different concentrations $(0,100,200$ and $250 \mu \mathrm{g} / \mathrm{ml})$ of RPMTG for $24 \mathrm{~h}$, and the cells were collected, washed with pre-cooled PBS, and resuspended in $300 \mu \mathrm{l} 1 \mathrm{X}$ Binding Buffer (BDBiosciences). The cells were stained with $5 \mu$ l Annexin V-FITC and $5 \mu \mathrm{l}$ PI for $15 \mathrm{~min}$ in the dark. Then, apoptotic cells were detected using flow cytometry (FACSCanto II; BD Biosciences), and FlowJo 7.6 software (FlowJo LLC) was used to determine the proportions (\%) of each subpopulation of cells.

Western blot analysis. Western blotting was used to determine changes in protein expression that were associated with RPMTG treatment. After treatment with RPMTG, the cells were collected and lysed in RIPA lysis buffer (Beyotime Institute of Biotechnology) containing protease and phosphatase inhibitors in an ice bath. Subsequently, the lysates were removed and the supernatant was collected by centrifugation at $10,000 \mathrm{x} \mathrm{g}$ for $10 \mathrm{~min}$ at $4^{\circ} \mathrm{C}$. The total protein concentration in each sample was determined using a BCA protein analysis kit (Tiangen Biotech Co., Ltd.). The protein samples (10 $\mu \mathrm{g} /$ lane) were loaded, separated via $10 \%$ SDS-PAGE, and subsequently transferred onto PVDF membranes (EMD Millipore). The membrane was incubated with blocking solution (5\% skimmed milk) at room temperature for $1 \mathrm{~h}$, and incubated with the corresponding primary antibodies overnight at $4^{\circ} \mathrm{C}$. The following primary antibodies were used: Bcl-2 (cat. no. 15071; Cell Signaling Technology, Inc.), Bcl-xL (cat. no. 10783-1-AP; ProteinTech Group, Inc.), induced myeloid leukaemia cell differentiation protein Mcl-1 (Mcl-1; cat. no. 16225-1-AP; ProteinTech Group, Inc.), cytochrome $c$ (cat. no. 11940; Cell Signaling Technology, Inc.), Bax (cat. no. 5023; Cell Signaling Technology, Inc.), Bad (cat. no. 10435-1-AP; ProteinTech Group, Inc.), cleaved caspase-9 (cat. no. 9509; Cell Signaling Technology, Inc.), cleaved caspase-3 (cat. no. 9661; Cell Signaling Technology, Inc.), cleaved poly(ADP)-ribose polymerase-1 (cleaved PARP-1; cat. no. 13371-1-AP; ProteinTech Group, Inc.), extracellular signal-regulated kinase (ERK; cat. no. 4696; Cell Signaling Technology, Inc.), phosphorylated (p-)ERK (cat. no. 4370; Cell Signaling Technology, Inc.), c-Jun n-terminal kinase (JNK; cat. no. 9252; Cell Signaling Technology, Inc.), p-JNK (cat. no. 4668; Cell Signaling Technology, Inc.), p38 (cat. no. 8690; Cell Signaling Technology, Inc.), p-p38 (cat. no. 4511; Cell Signaling Technology, Inc.), cyclin A (cat. no. 18202-1-AP; ProteinTech Group, Inc.), cyclin D (cat. no. 60186-1-AP; ProteinTech Group, Inc.), cyclin-dependent kinase 2 (CDK2; cat. no. 10122-1-AP; ProteinTech Group, Inc.), p21 (cat. no. 103551-AP; ProteinTech Group,Inc.) and $\beta$-actin (cat.no. 3700; Cell Signaling Technology, Inc.). These primary antibodies were used at 1:1,000 dilution. After washing three times with TBS with Tween-20 (0.05\%), the membranes were subsequently incubated with anti-mouse IgG, HRP-conjugated antibody (cat. no. 7076; Cell Signaling Technology, Inc.) or anti-rabbit IgG HRP-conjugated antibody (cat. no. 7074; Cell Signaling Technology, Inc.) for $1 \mathrm{~h}$ at room temperature. The secondary antibodies were used at 1:5,000 dilution. Positive antibody binding was then visualized by ECL detection (Wuhan Boster Biological Technology Co., Ltd.). Finally, ImageJ software (version 1.8.0; National Institutes of Health) was used for densitometry.

Statistical analysis. All data are expressed as the mean \pm SD of at least three independent experiments. Statistical analysis was performed using SPSS 22.0 software (IBM Corp.) and GraphPad Prism 8.0 software (GraphPad Software, Inc.). One way ANOVA was used for statistical analysis, followed by Bonferroni's post hoc test. $\mathrm{P}<0.05$ was considered to indicate a statistically significant difference.

\section{Results}

RPMTG inhibits the proliferation of HCT116 and SW620 cells. HCT116 and SW620 cells were treated with different concentrations of RPMTG $(100-500 \mu \mathrm{g} / \mathrm{ml})$ for 12 and $24 \mathrm{~h}$, and cell viability was determined by the MTT assay. As shown in Fig. 1A and B, 

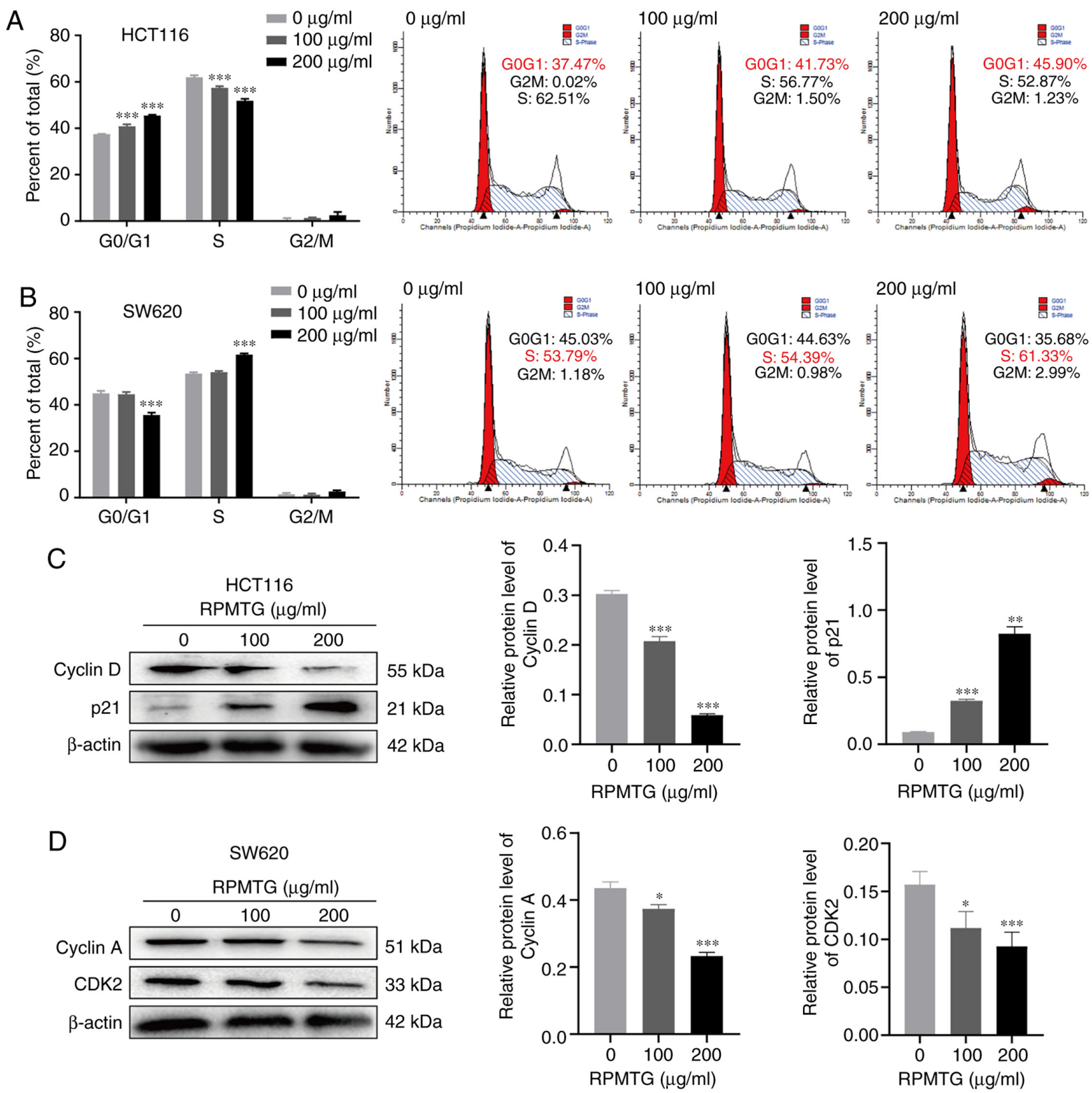

Figure 2. RPMTG induces cell cycle arrest in HCT116 and SW620 cells. Flow cytometry was used to determine the cell cycle distribution and ratio of (A) HCT116 and (B) SW620 cells treated with RPMTG at concentrations of 0, 100 and $200 \mu \mathrm{g} / \mathrm{ml}$ for $24 \mathrm{~h}$. (C) Western blot analysis of cyclin D and p21 expression in HCT116 cells after treatment with RPMTG. (D) Western blot analysis of CDK2 and cyclin A expression in SW620 cells after treatment with RPMTG. The integrated band density was determined by ImageJ software, and $\beta$-actin served as the internal control. Data are expressed as the mean \pm SD from three independent experiments. ${ }^{*} \mathrm{P}<0.05,{ }^{* *} \mathrm{P}<0.01$ and ${ }^{* * * *} \mathrm{P}<0.001$ vs. control group. RPMTG, total saponins from Rhizoma Panacis Majoris; CDK, cyclin-dependent kinase.

cell viability decreased with increasing RPMTG concentrations, and the proliferation inhibition rate increased gradually. The $\mathrm{IC}_{50}$ values of HCT116 cells at 12 and $24 \mathrm{~h}$ were 424.4 and $315.8 \mu \mathrm{g} / \mathrm{ml}$, respectively; the $\mathrm{IC}_{50}$ values of SW620 cells at 12 and $24 \mathrm{~h}$ were 386.2 and $355.1 \mu \mathrm{g} / \mathrm{ml}$, respectively.

RPMTG induces cell cycle arrest in HCT116 and SW620 cells. To determine whether RPMTG-induced inhibition of cell proliferation was mediated via cell cycle arrest, flow cytometry analysis was performed (Fig. 2). HCT116 and SW620 cells were treated with RPMTG $(0,100$ and $200 \mu \mathrm{g} / \mathrm{ml})$. As shown in Fig. 2, compared with the control group, HCT116 and SW620 cells were arrested at the $\mathrm{G}_{0} / \mathrm{G} 1$ and $\mathrm{S}$ phase, respectively; the percentage of HCT 116 cells in the $\mathrm{G}_{0} / \mathrm{G}_{1}$ phase increased from
37.47 to $45.90 \%$ (Fig. 2A), and the percentage of SW620 cells in the $\mathrm{S}$ phase increased from 53.79 to $66.89 \%$ (Fig. 2B). In addition, western blotting demonstrated that the expression levels of the $G_{0} / G_{1}$ phase-associated proteins cyclin D and p21 were decreased and increased, respectively, by RPMTG treatment in HCT116 cells (Fig. 2C). However, the expression levels of the $\mathrm{S}$ phase-associated proteins cyclin A and CDK2 were decreased in SW620 cells (Fig. 2D). These results revealed that the inhibition of the proliferation of HCT116 and SW620 cells by RPMTG was mediated via cell cycle arrest at the $\mathrm{G}_{0} / \mathrm{G}_{1}$ and $\mathrm{S}$ phases.

RPMTG induces morphological changes and apoptosis in HCT116 and SW620 cells. DAPI staining was used to evaluate 
A

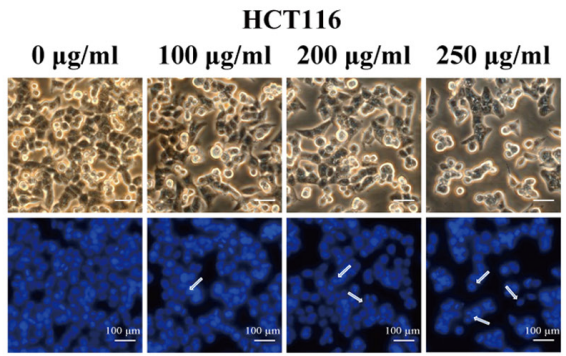

B

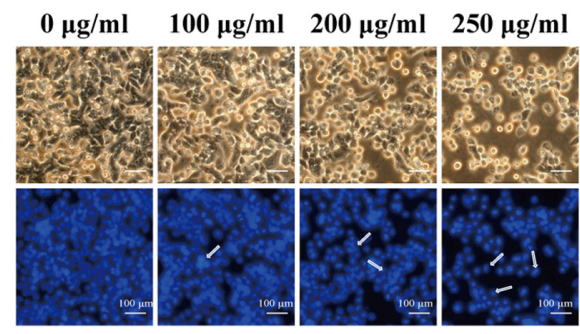

HCT116

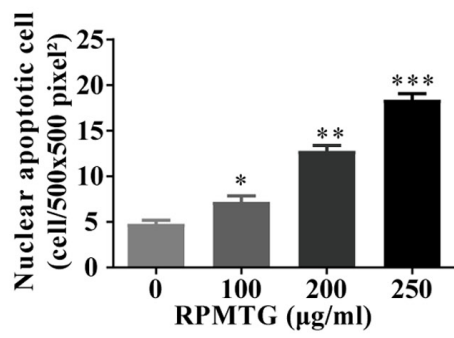

SW620

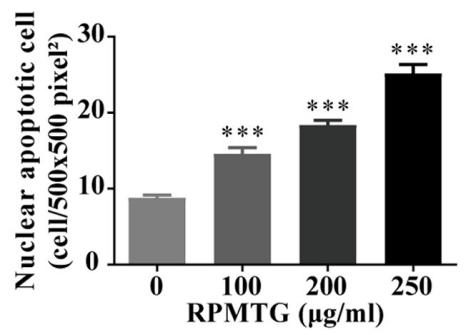

HCT116

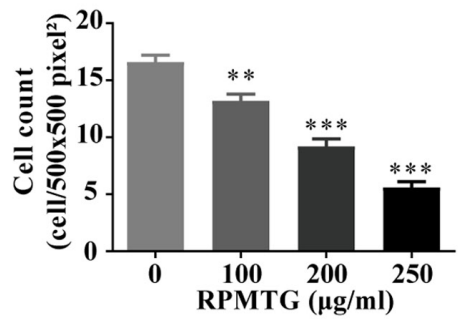

SW620

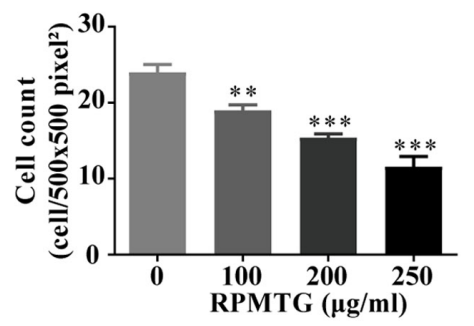

C

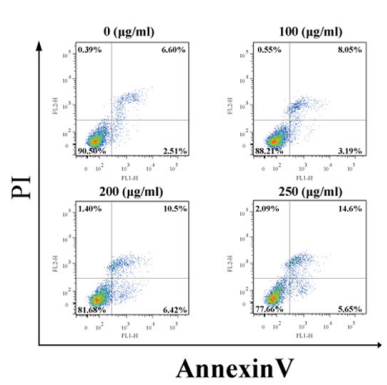

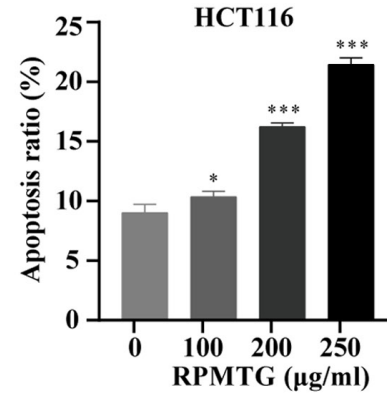

D

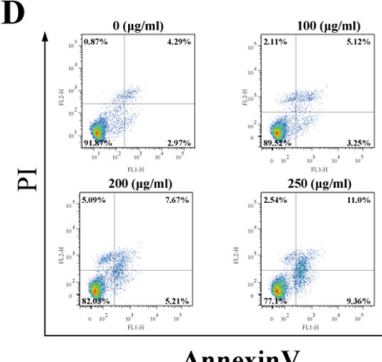

SW620

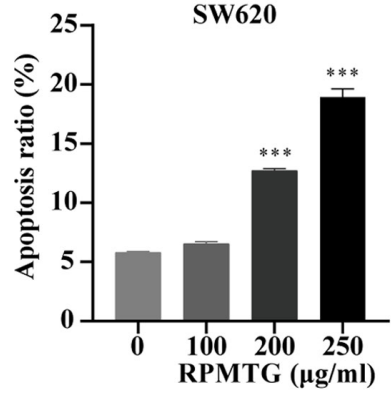

Figure 3. RPMTG induces morphological changes and induces apoptosis in HCT116 and SW620 cells. (A) HCT116 and (B) SW620 cells were treated with RPMTG at increasing concentrations $(0,100,200$ and $250 \mu \mathrm{g} / \mathrm{ml})$ for $24 \mathrm{~h}$, following which, shrinkage was observed, with condensation of nuclear chromatin, marginalization and chromatin DNA breaks. Scale bar, $100 \mu \mathrm{m}$. (C) HCT116 and (D) SW620 cells were treated with RPMTG $(0,100,200 \mathrm{and} 250 \mu \mathrm{g} / \mathrm{ml})$ for $24 \mathrm{~h}$ and analysed by Annexin V/PI flow cytometry. The lower right quadrant indicates the percentage of early apoptotic cells. Data are expressed as the mean \pm SD from three independent experiments. ${ }^{*} \mathrm{P}<0.05,{ }^{* * *} \mathrm{P}<0.01$ and ${ }^{* * * *} \mathrm{P}<0.001$ vs. control group. RPMTG, total saponins from Rhizoma Panacis Majoris.

the specific morphological changes. The results are shown in Fig. 3A and B. It was observed that the nuclear structure of control cells was not altered, whereas, after RPMTG $(0$, 100,200 and $250 \mu \mathrm{g} / \mathrm{ml}$ ) treatment for $24 \mathrm{~h}$, the cells exhibited changes in the nuclear structure, such as shrunk, fragmented nuclei. The proportion of cells with nuclear apoptosis has increased in a dose-dependent manner. Furthermore, the mean cell count of 10 selected fields $\left(500 \times 500\right.$ pixel $\left.^{2}\right)$ in the images was calculated (Fig. 3A and B). The results indicated that RPMTG treatment induced cell apoptosis.

To further verify whether RPMTG induced cell apoptosis, RPMTG $(0,100,200$ and $250 \mu \mathrm{g} / \mathrm{ml})$ was used to treat HCT116 and SW620 cells for $24 \mathrm{~h}$, and then flow cytometry was performed to detect the proportion of apoptotic cells. As shown in Fig. 3C and D, the total percentage of apoptotic cells among HCT116 and SW620 cells treated with $250 \mu \mathrm{g} / \mathrm{ml}$ RPMTG was 21.40 and $18.63 \%$, respectively. These results demonstrated that RPMTG treatment induced apoptosis of HCT116 and SW620 cells.

RPMTG affects the expression of mitochondrial pathway-related proteins in HCT116 and SW62O cells. The effects of RPMTG on the expression levels of mitochondrial apoptosis-related proteins (Bcl-2, Bcl-xL, Mcl-1, cytochrome $c$,
Bax, Bad, cleaved caspase- 9 , cleaved caspase- 3 and cleaved PARP-1) in HCT116 and SW620 cells were detected. As shown in Fig. 4A and B, following RPMTG treatment, the expression levels of the anti-apoptotic Bcl-2, Bcl-xL and Mcl-1 proteins were reduced, whereas the expression levels of cytochrome $c$, Bax, Bad, cleaved caspase- 9 , cleaved caspase- 3 and cleaved PARP-1 were increased. Thus suggesting that RPMTG could induce the release of cytochrome $c$ into the cytoplasm and then activate the downstream caspase cascade involving caspase-9 and caspase-3. These results indicated that the apoptosis of CRC cells induced by RPMTG was associated with the mitochondrial pathway.

RPMTG regulates mitogen-activated protein kinase (MAPK) signalling in HCT116 and SW620 cells. Subsequently, the effect of RPMTG on the MAPK signalling pathway was investigated, as this pathway has been demonstrated to be important in cancer cell apoptosis, ERK regulates cell proliferation and differentiation, whereas JNK and p38 activation are related to apoptosis $(17,18)$. As shown in Fig. 5A and B, the expression ratio of p-ERK/ERK was decreased, whereas p-JNK/JNK and p-p38/p38 ratios were increased. The results demonstrated that the induction of CRC cell apoptosis by RPMTG may be mediated via the MAPK signalling pathway. 
A

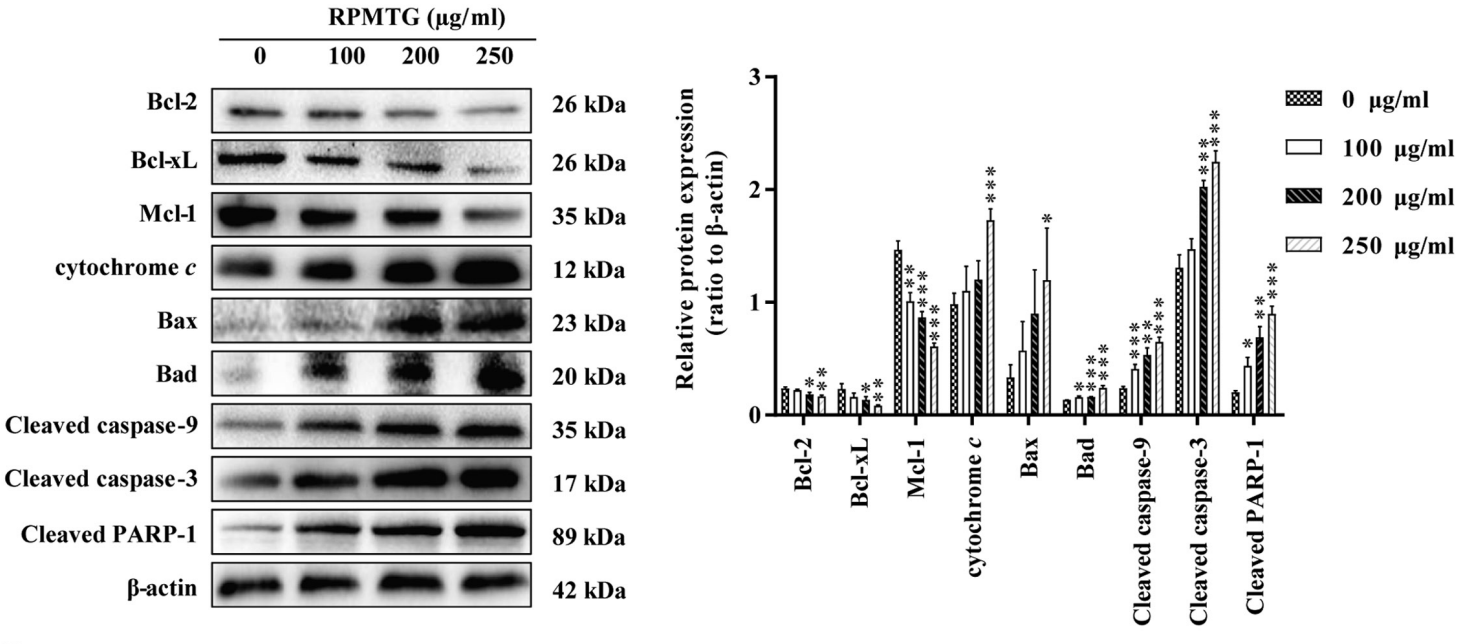

B

SW620 RPMTG $(\mu \mathrm{g} / \mathrm{ml})$
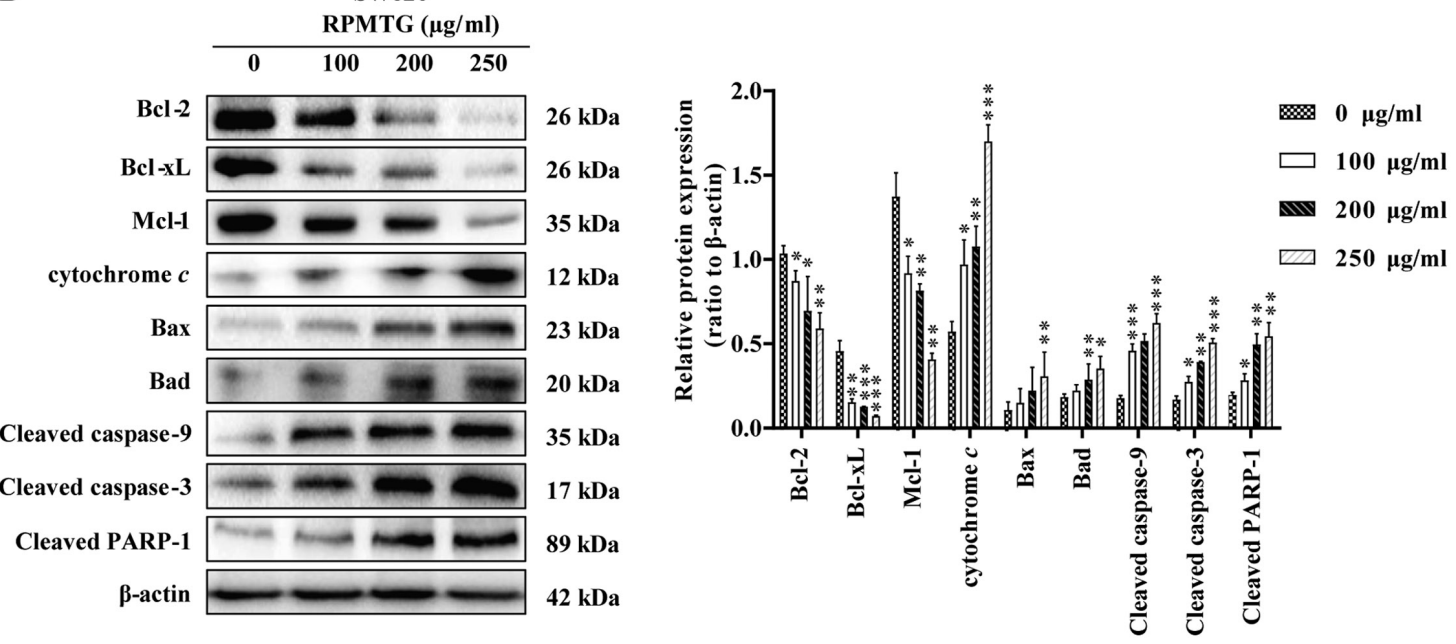

Figure 4. RPMTG affects the expression of mitochondrial pathway-related proteins in HCT116 and SW620 cells. The expression of apoptosis-related proteins was detected by western blotting. (A) HCT116 and (B) SW620 cells were treated with different concentrations of RPMTG (0, 100, 200 and 250 $\mu \mathrm{g} /$ $\mathrm{ml}$ ) for $24 \mathrm{~h}$, and then the expression levels of Bcl-2, Bcl-xL, Mcl-1, cytochrome $c$, Bax, Bad, cleaved caspase-9, cleaved caspase-3 and cleaved PARP-1 were detected by western blotting. ImageJ software was used to determine the density ratio of each protein band to the $\beta$-actin band. Data are expressed as the mean \pm SD of three independent experiments. ${ }^{*} \mathrm{P}<0.05,{ }^{* *} \mathrm{P}<0.01$ and ${ }^{* * * *} \mathrm{P}<0.001$ vs. control group. RPMTG, total saponins from Rhizoma Panacis Majoris; PARP-1, poly(ADP)-ribose polymerase-1; Mcl-1, induced myeloid leukaemia cell differentiation protein Mcl-1.

To further confirm whether the apoptosis induced by RPMTG was dependent on the JNK and p38 MAPK signalling pathways, HCT116 and SW620 cells were pretreated with JNK and p38 inhibitors (SP600125 and SB203580, respectively), and then treated with RPMTG $(250 \mu \mathrm{g} / \mathrm{ml})$. The MTT assay demonstrated that the combination of RPMTG with SP600125 or SB203580 could markedly reverse the inhibitory effect of RPMTG on cell viability (Fig. 6A and B). In addition, the western blotting results revealed that the combination of RPMTG with SP600125 or SB203580 could reduce the expression levels of $\mathrm{p}-\mathrm{JNK}, \mathrm{p}-\mathrm{p} 38$, the pro-apoptotic proteins Bax and cleaved caspase- 3 , and increase the expression of the anti-apoptotic protein Bcl-2 (Fig. 7A and B). These results suggested that RPMTG-induced apoptosis was associated with the activation of the JNK and p38 MAPK signalling pathways.

\section{Discussion}

CRC clinical chemotherapy is restricted by systemic toxicity, such as moderate myelosuppression, nausea, vomiting, diarrhoea and other adverse reactions (4). Adjuvant chemotherapy is only effective in $25 \%$ of patients, which indicates that $>70 \%$ of patients suffer more from the toxic effects, rather than experiencing the therapeutic benefits (3-6). Furthermore, the 5-year survival rate for CRC is $<10 \%$ (19). Therefore, new drugs for CRC with high efficiency and low toxicity are urgently needed. Saponins in natural medicines with a broad range of pharmacological activities have been attracting increasing attention, among which ginsenosides derived from $P$. ginseng have been found to play an important role in the prevention and treatment of cancer (10). For example, total ginsenosides can induce human non-small cell lung cancer cell death (20), whereas ginsenoside $\mathrm{Rh}_{2}$ has been reported to inhibit human prostate and breast cancer cell proliferation $(21,22)$. In particular, ginsenoside $\mathrm{Rg}_{3}$ has been approved for clinical use, either alone, which has been shown to inhibit the proliferation of CRC and breast cancer cells $(23,24)$, or as a supplement to chemotherapy drugs, such as Adriamycin in liver cancer and cyclophosphamide in lung cancer $(25,26)$. RPMTG was extracted from the roots 

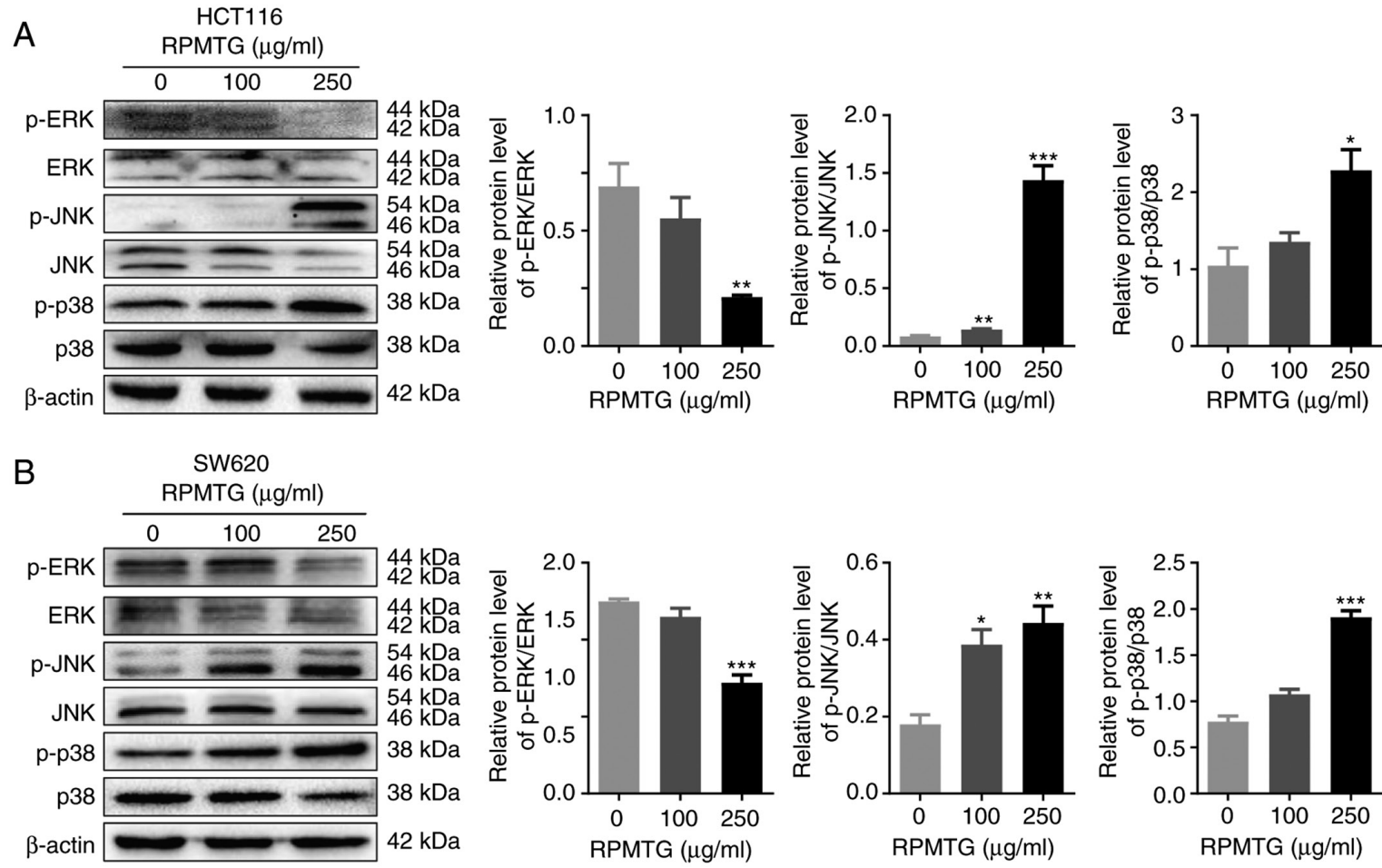

Figure 5. RPMTG regulates MAPK signalling in HCT116 and SW620 cells. (A) HCT116 and (B) SW620 cells were treated with different concentrations of RPMTG $(0,100$ and $250 \mu \mathrm{g} / \mathrm{ml})$ for $24 \mathrm{~h}$, and the protein expression levels of the MAPK signalling pathway-related proteins p-ERK, ERK, p-JNK, JNK, p-p38 and p38 were evaluated by western blotting. ImageJ software was used to determine the density ratio of each phosphorylated protein band to its total protein counterpart. Data are expressed as the mean $\pm \mathrm{SD}$ of three independent experiments. ${ }^{*} \mathrm{P}<0.05,{ }^{* *} \mathrm{P}<0.01$ and ${ }^{* * *} \mathrm{P}<0.001$ vs. control group. RPMTG, total saponins from Rhizoma Panacis Majoris; ERK, extracellular signal-regulated kinase; JNK, c-Jun N-terminal kinase; p-, phosphorylated; MAPK, mitogen-activated protein kinase.

A

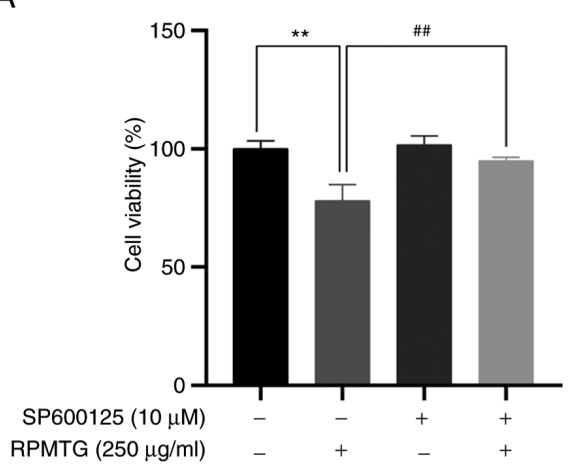

B

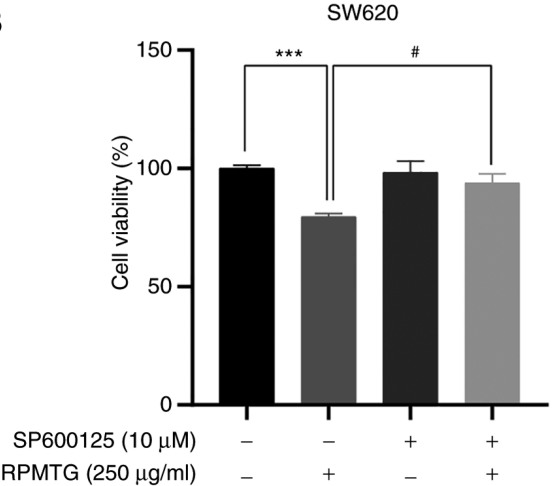

HCT116

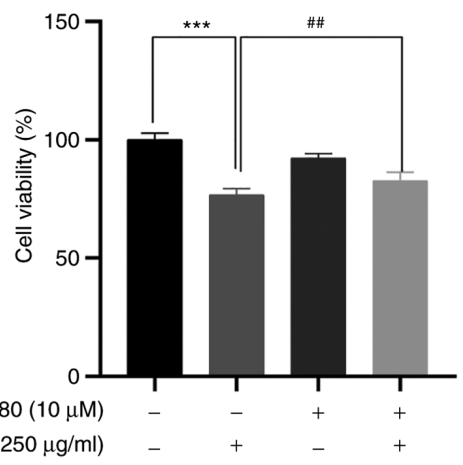

$\operatorname{RPMTG}(250 \mu \mathrm{g} / \mathrm{ml})$

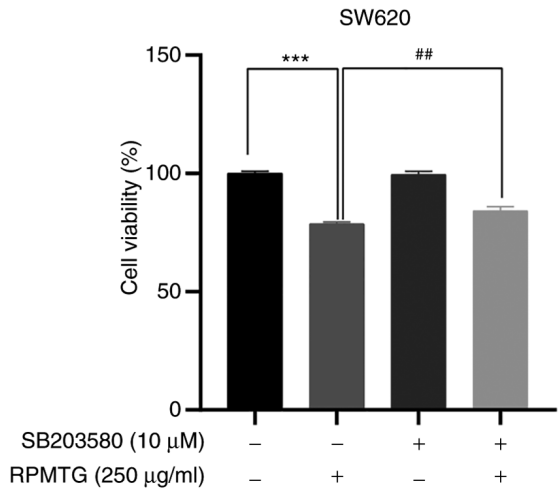

Figure 6. Effect of JNK and p38 inhibitors on the viability of HCT116 and SW620 cells. The two cell types were pretreated with JNK inhibitor (SP600125) and p38 inhibitor (SB203580) for $2 \mathrm{~h}$, and then treated with $250 \mu \mathrm{g} / \mathrm{ml} \mathrm{RPMTG}$ for $24 \mathrm{~h}$. (A) MTT assay revealed the effects of the JNK inhibitor (SP600125) and p38 inhibitor (SB203580) on the viability of HCT116 cells. (B) MTT assay revealed the effects of the JNK inhibitor (SP600125) and p38 inhibitor (SB203580) on the viability of SW620 cells. Data are expressed as the mean $\pm \mathrm{SD}$ of three independent experiments. ${ }^{* * *} \mathrm{P}<0.01$ and ${ }^{* * * *} \mathrm{P}<0.001 \mathrm{vs}$. control group; ${ }^{*} \mathrm{P}<0.05$, ${ }^{\# \#} \mathrm{P}<0.001$ vs. RPMTG group. RPMTG, total saponins from Rhizoma Panacis Majoris; JNK, c-Jun N-terminal kinase. 


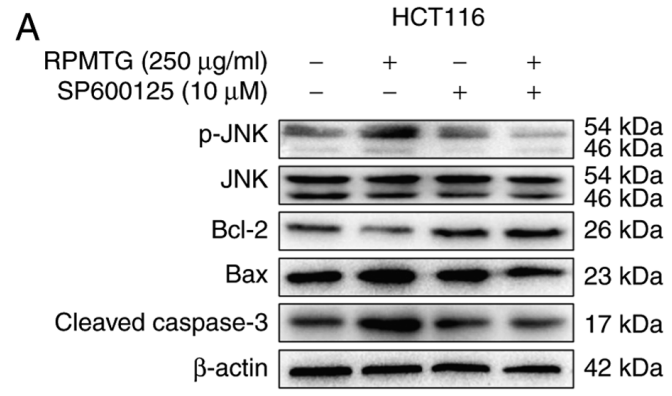

HCT116
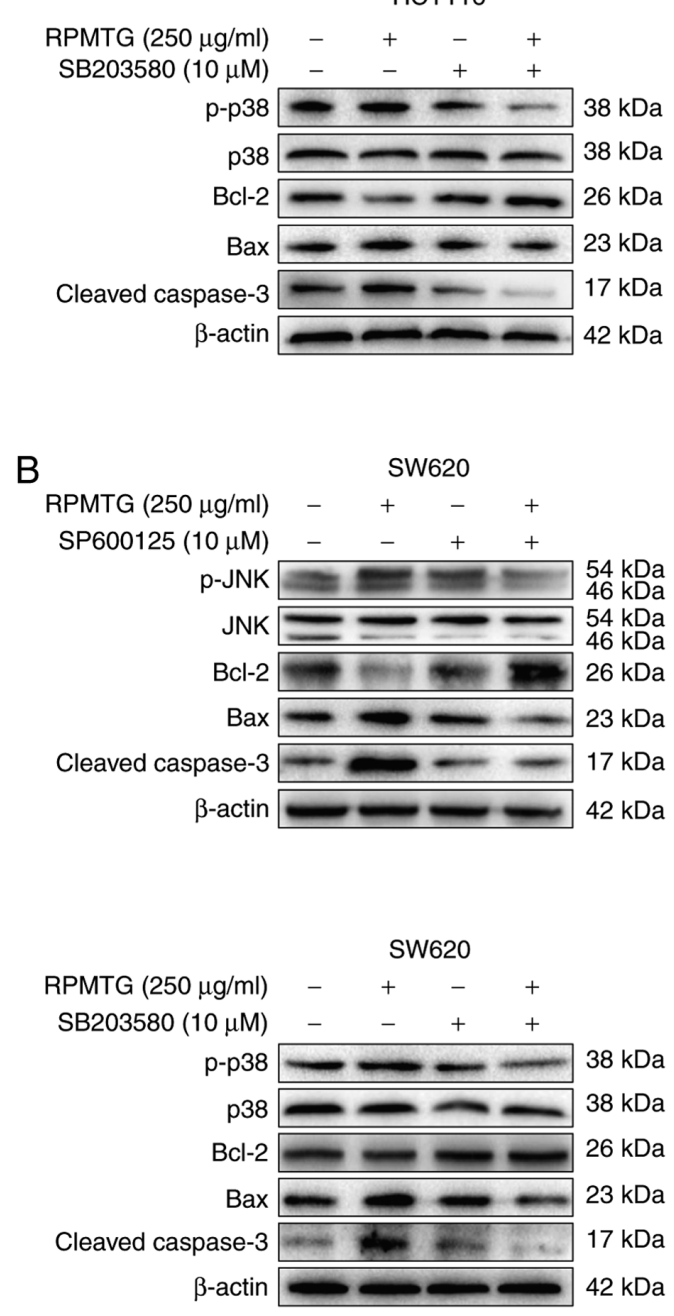

HCT116

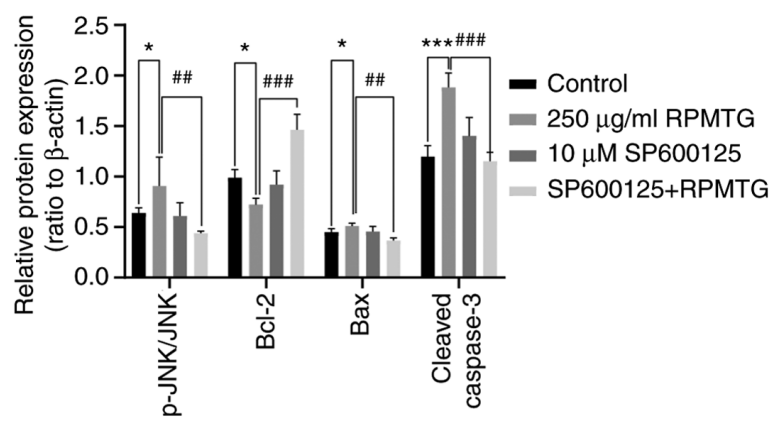

HCT116

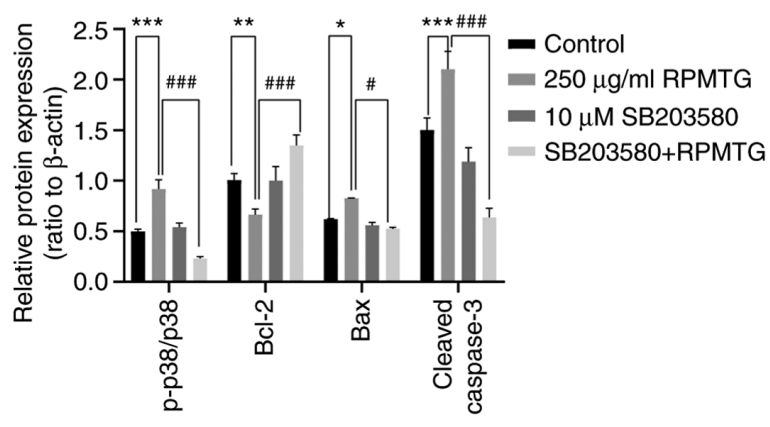

SW620

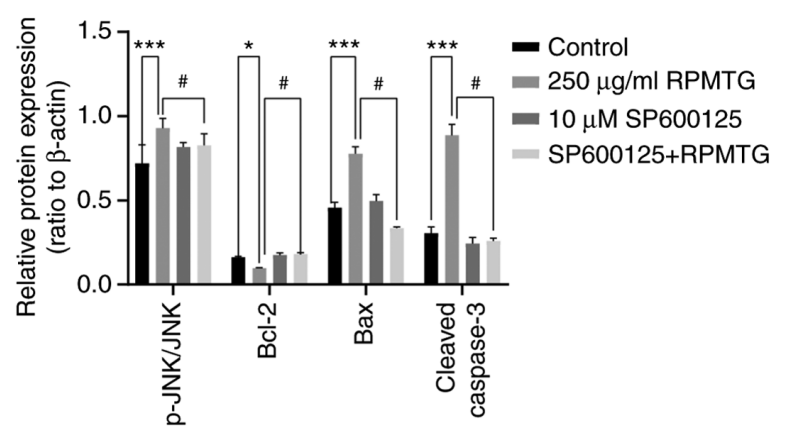

SW620

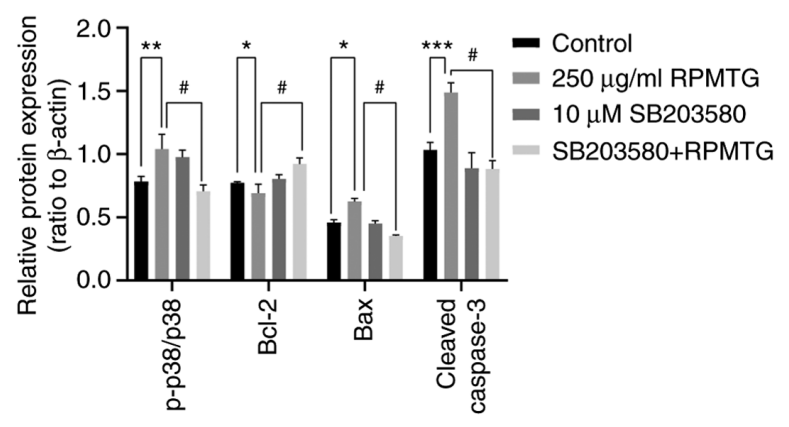

Figure 7. Effect of JNK inhibitor and p38 inhibitor on the apoptosis of HCT116 and SW620 cells. The two cell types were pretreated with JNK inhibitor (SP600125) and p38 inhibitor (SB203580) for $2 \mathrm{~h}$, and then treated with $250 \mu \mathrm{g} / \mathrm{ml}$ RPMTG for $24 \mathrm{~h}$. Western blot analysis of the expression of p-JNK, total JNK, p-p38, total p38, Bcl-2, Bax and cleaved caspase-3 in (A) HCT116 and (B) SW620 cells. ImageJ software was used to determine the density ratio of the p-JNK and p-p38 bands relative to total protein content in SW620 cells, and the density ratio of the Bcl-2, Bax and cleaved caspase- 3 bands relative to the $\beta$-actin band. Data are expressed as the mean $\pm \mathrm{SD}$ of three independent experiments. ${ }^{*} \mathrm{P}<0.05,{ }^{* * *} \mathrm{P}<0.01$ and ${ }^{* * * *} \mathrm{P}<0.001$ vs. control group; ${ }^{\#} \mathrm{P}<0.05$, ${ }^{\# \#} \mathrm{P}<0.01$ and

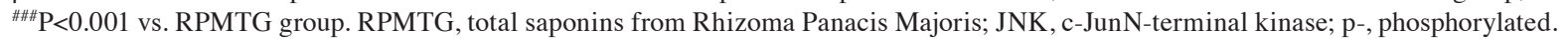

of $P$. japonicus var. Major, a species in the Panax genus of the Araliaceae family as $P$. ginseng. After being processed by macroporous resin column chromatography, the content of saponins in RPMTG reached $73.09 \%$ as detected by UV spectrophotometry, and 15 ginsenosides were determined by HPLC-ESI-MS/MS, which indicated that RPMTG may be effective against tumour cells. Therefore, the present study was undertaken to investigate the effects of RPMTG against CRC cells.

The results demonstrated that RPMTG exerted an anti-CRC effect by inhibiting cell proliferation, inducing cell cycle arrest and promoting apoptosis of HCT116 and SW620 cells. The MTT assay revealed that the proliferation of HCT116 and SW620 cells treated with RPMTG was significantly 
reduced in a dose-dependent manner, suggesting that RPMTG exerted an antiproliferative effect on CRC cells (Fig. 1). It is worth noting that the $\mathrm{IC}_{50}$ screening results of MTT test were between 300-400, but in the process of the experiment, it was found that its efficacy was too significant. In order to improve the detection of protein, the maximum concentration of $250 \mu \mathrm{g} / \mathrm{ml}$ was chosen. The cell cycle is crucial for the control of cell proliferation. It is commonly known that the expression of the cyclin/CDK complex plays a pivotal role in $\mathrm{G}_{0} / \mathrm{G}_{1}$ and $S$ phase progression. During the $G_{0} / G_{1}$ phase, cyclin D binds with CDK2 or CDK4 to promote cell cycle progression, and is highly expressed (27). The CDK inhibitor p21 acts as a cell cycle inhibitor by inhibiting the binding process, thereby leading to cell cycle arrest in the $G_{0} / G_{1}$ phase (28). During the $S$ phase, cyclin A partners with CDK2 to initiate DNA replication from preformed replication initiation complexes, accelerating the process of cell division from the $S$ to the $G_{2}$ phase (29). The results of the present study demonstrated that RPMTG treatment inhibited the expression of cyclins A and D and CDK2 activity, causing $\mathrm{G}_{0} / \mathrm{G}_{1}$ and $\mathrm{S}$ phase arrest of HCT116 and SW620 cells, respectively (Fig. 2).

Apoptosis is an orderly and closely regulated cell death process, and the change in cell morphology is an important mechanism underlying drug-induced apoptosis (30). Accordingly, the induction of apoptosis in CRC cells may be beneficial for controlling the progression of CRC $(31,32)$. In the present study, RPMTG treatment induced cell atrophy and typical apoptotic characteristics, such as chromatin condensation, apoptotic body formation, nuclear condensation and fragmentation (Fig. 3A and B). Moreover, apoptosis in the early and late stages was observed by flow cytometry analysis (Fig. 3C and D). Mitochondrial apoptosis mediated by the increase of mitochondrial outer membrane permeability is an important cell apoptotic pathway (30). This pathway is mainly regulated by the balance between the expression levels of pro-apoptotic and anti-apoptotic proteins of the Bcl-2 family (33). The balance between anti-apoptotic (such as Bcl-2 and Bcl-xL) and pro-apoptotic (such as Bax and Bad) members may be disrupted when apoptosis occurs, which may lead to the increased permeability of the mitochondrial membrane and the release of cytochrome $\mathrm{c}$ into the cytoplasm, causing activation of the downstream caspase family $(34,35)$. In the present study, RPMTG treatment decreased the expression of the anti-apoptotic Bcl-2 and Bcl-xL proteins, whereas it increased the expression of the pro-apoptotic Bax and Bad proteins. In addition, the levels of cleaved caspase- 9 and cleaved caspase- 3 in the cytoplasm were increased, along with the increased levels of cytochrome $c$ in the cytoplasm (Fig. 4). These results suggested that RPMTG may induce apoptosis of HCT116 and SW620 cells through mitochondrial-related pathways.

The MAPK signalling pathways regulate cell proliferation, differentiation, apoptosis, migration and other cell processes, in response to environmental signals associated with cell proliferation and metabolism (36,37). MAPK family members expressed in CRC mainly include ERK, JNK and p38 (38). It has been reported that ERK is a positive regulator of cell survival (17). Furthermore, JNK and p38 MAPK are responsible for a variety of stress responses and participate in the regulation of apoptosis (18). In the present study, the expression ratio of p-ERK/ERK was decreased, while $\mathrm{p}-\mathrm{JNK} / \mathrm{JNK}$ and $\mathrm{p}-\mathrm{p} 38 / \mathrm{p} 38$ were significantly increased in a dose-dependent manner following RPMTG treatment (Fig. 5). Of note, compared with RPMTG treatment, the addition of the JNK inhibitor SP600125 and the p38 inhibitor SB203580 markedly reversed the inhibitory effect on cell proliferation and the induction of apoptosis (Figs. 6 and 7), suggesting that RPMTG may induce apoptosis of HCT116 and SW620 cells via the MAPK signalling pathways.

While the present study suggested that RPMTG may exert a therapeutic effect in CRC, future in vivo experimental models are required to substantiate the results obtained. Additionally, as the effects of saponins possess surface-active characteristics due to the amphiphilic nature of their chemical structure, and saponin treatment has been found to increase cell membrane permeability $(39,40)$, further investigation is warranted, and thus these are the main areas of interest for our next study.

In conclusion, the present study demonstrated that RPMTG inhibited cell proliferation, caused cell cycle arrest in the $\mathrm{G}_{0} / \mathrm{G}_{1}$ and $\mathrm{S}$ phase and induced apoptosis of CRC cells by regulating the activation of mitochondrial-related and MAPK signalling pathways. These findings uncovered the molecular mechanism through which RPMTG induces cancer cell apoptosis and indicated that RPMTG may be valuable as a supplementary drug for the treatment of CRC.

\section{Acknowledgements}

Not applicable.

\section{Funding}

This work was supported by grants from the National Natural Science Foundation (grant nos. 81803946 and 81773919), the Key Scientific Research Plan of Shaanxi Shaanxi Education Department 2020 (grant no. 20JY010) and Subject Innovation Team of Shaanxi University of Chinese Medicine (grant no. 2019-YS01), Key Industry Innovation Chain (group) Project of Shaanxi Provincial Science and Technology Department (grant no. 2020ZDLSF05-08), Subsidy Project of Xianyang Comprehensive Experimental Station of National Technical System of Chinese Medicinal Materials Industry (grant no. 2019JCW-06).

\section{Availability of data and materials}

The datasets used and/or analysed during the current study are available from the corresponding author on reasonable request.

\section{Authors' contributions}

RZ, YH and ZY conceived and designed the present study. ZT and $\mathrm{ZY}$ provided administrative support. Learning materials were provided by YL and YP. LC, YP, YH and MM conducted the experiment. LC, ZT, YL and JH conducted data analysis and interpretation. LC, ZY and YH confirm the authenticity of all the raw data. LC, RZ and ZY wrote the manuscript. All authors read and approved the final manuscript. 


\section{Ethics approval and consent to participate}

Not applicable.

\section{Patient consent for publication}

Not applicable.

\section{Competing interests}

The authors declare that they have no competing interests.

\section{References}

1. Bray F, Ferlay J, Soerjomataram I, Siegel RL, Torre LA and Jemal A: Global cancer statistics 2018: GLOBOCAN estimates of incidence and mortality worldwide for 36 cancers in 185 countries. CA Cancer J Clin 68: 394-424, 2018.

2. Arnold M, Sierra MS, Laversanne M, Soerjomataram I, Jemal A and Bray F: Global patterns and trends in colorectal cancer incidence and mortality. Gut 66: 683-691, 2017.

3. Ma M, Wang X, Liu N, Shan F and Feng Y: Low-dose naltrexone inhibits colorectal cancer progression and promotes apoptosis by increasing M1-type macrophages and activating the Bax/Bcl-2/ caspase-3/PARP pathway. Int Immunopharmacol 83: 106388, 2020

4. Sun J, Feng Y, Wang Y, Ji Q, Cai G, Shi L, Wang Y, Huang Y, Zhang $\mathrm{J}$ and $\mathrm{Li} \mathrm{Q}$ : $\alpha$-hederin induces autophagic cell death in colorectal cancer cells through reactive oxygen species dependent AMPK/mTOR signaling pathway activation. Int J Oncol 54 1601-1612, 2019.

5. Liu Z, Xiong L, Ouyang G, Ma L, Sahi S, Wang K, Lin L, Huang H, Miao X, Chen W, et al: Investigation of copper cysteamine nanoparticles as a new type of radiosensitiers for colorectal carcinoma Treatment. Sci Rep 7: 9290, 2017.

6. Hu M, Yu Z, Mei P, Li J, Luo D, Zhang H, Zhou M, Liang F and Chen R: Correction for: Lycorine induces autophagy-associated apoptosis by targeting MEK2 and enhances vemurafenib activity in colorectal cancer. Aging (Albany NY) 12: 6488-6489, 2020.

7. Weaver BA: How Taxol/paclitaxel kills cancer cells. Mol Biol Cell 25: 2677-2681, 2014

8. GLB: L. Gatti, Perego P and Zaffaroni N: Camptothecin resistance in cancer: Insights into the molecular mecha-nisms of a DNA-damaging drug. Curr Med Chem 20: 1541-1565, 2013.

9. Paidakula S, Nerella S, Vadde R, Kamal A and Kankala S: Design and synthesis of $4 \beta$-acetamidobenzofuranone-podophyllotoxin hybrids and their anti-cancer evaluation. Bioorg Med Chem Lett 29: 2153-2156, 2019.

10. Man S, Gao W, Zhang Y, Huang L and Liu C: Chemical study and medical application of saponins as anti-cancer agents. Fitoterapia 81: 703-714, 2010.

11. Choi JS, Chun KS, Kundu J and Kundu JK: Biochemical basis of cancer chemoprevention and/or chemotherapy with ginsenosides (Review). Int J Mol Med 32: 1227-1238, 2013.

12. Lee DG, Jang SI, Kim YR, Yang KE, Yoon SJ, Lee ZW, An HJ, Jang IS, Choi JS and Yoo HS: Anti-proliferative effects of ginsenosides extracted from mountain ginseng on lung cancer. Chin J Integr Med 22: 344-352, 2016.

13. Sun M, Ye Y, Xiao L, Duan X, Zhang Y and Zhang H: Anticancer effects of ginsenoside Rg3 (Review). Int J Mol Med 39: 507-518, 2017.

14. Song X, Wang W, Zhang X, Jiang Y, Yang X, Deng C, Yue Z and Tang Z: Deglucose chikusetsusaponin IVa isolated from Rhizoma Panacis Majoris induces apoptosis in human HepG2 hepatoma cells. Mol Med Rep 12: 5494-5500, 2015.

15. Chen T, Chen LF, Jin GQ and Li D: Panax japlcus var induced apoptosis of human hepatocarcinoma cells in vitro. Tumor 26:144-147, 2006 (In Chinese).

16. Chen T, Chen M, Hu Y, Gong Z and Deng L: Extraction and anticancer activity of polysaccharide from Rhizoma Panacis Majoris. Chinese Journal of Traditional Chinese Medicine 35: 912-914, 2010 (In Chinese)

17. Sun Y, Liu WZ, Liu T, Feng X, Yang N and Zhou HF: Signaling pathway of MAPK/ERK in cell proliferation, differentiation, migration, senescence and apoptosis. J Recept Signal Transduct Res 35: 600-604, 2015.
18. Wagner EF and Nebreda ÁR: Signal integration by JNK and p38 MAPK pathways in cancer development. Nat Rev Cancer 9: 537-549, 2009.

19. Pagès PB, Le Pimpec-Barthes F and Bernard A: Surgery for pulmonary metastases from colorectal cancer: Predictive factors for survival. Rev Mal Respir 33: 838-852, 2016 (In French).

20. Zhao M, Chen Q, Xu W, Wang H, Che Y, Wu M, Wang L, Lijuan $\mathrm{C}$ and $\mathrm{Hao} \mathrm{H}$ : Total ginsenosides extract induce autophagic cell death in NSCLC cells through activation of endoplasmic reticulum stress. J Ethnopharmacol 243: 112093, 2019.

21. Huang Y, Huang H, Han Z, Li W, Mai Z and Yuan R: Ginsenoside $\mathrm{Rh} 2$ inhibits angiogenesis in prostate cancer by targeting CNNM1. J Nanosci Nanotechnol 19: 1942-1950, 2019.

22. Jeong D, Ham J, Park S, Kim HW, Kim H, Ji HW and Kim SJ: Ginsenoside Rh2 suppresses breast cancer cell proliferation by epigenetically regulating the long noncoding RNA C3orf67-AS1. Am J Chin Med 47: 1643-1658, 2019.

23. Tang YC, Zhang Y, Zhou J, Zhi Q, Wu MY, Gong FR, Shen M, Liu L, Tao M, Shen B, et al: Ginsenoside Rg3 targets cancer stem cells and tumor angiogenesis to inhibit colorectal cancer progression in vivo. Int J Oncol 52: 127-138, 2018.

24. Nakhjavani M, Hardingham JE, Palethorpe HM, Tomita Y, Smith E, Price TJ and Townsend AR: Ginsenoside Rg3: Potential Molecular Targets and Therapeutic Indication in Metastatic Breast Cancer. Medicines (Basel) 6: 17, 62019.

25. Kim DG, Jung KH, Lee DG, Yoon JH, Choi KS, Kwon SW, Shen HM, Morgan MJ, Hong SS and Kim YS: 20(S)-Ginsenoside $\mathrm{Rg} 3$ is a novel inhibitor of autophagy and sensitizes hepatocellular carcinoma to doxorubicin. Oncotarget 5: 4438-4451, 2014

26. Zhang Q, Kang X and Zhao W: Antiangiogenic effect of low-dose cyclophosphamide combined with ginsenoside $\mathrm{Rg} 3$ on Lewis lung carcinoma. Biochem Biophys Res Commun 342: 824-828, 2006.

27. Coffman JA: Cell cycle development. Dev Cell 6: 321-327, 2004

28. Park M-T and Lee S-J: Cell cycle and cancer. J Biochem Mol Biol 36: 60-65, 2003.

29. Schafer KA: The cell cycle: A review. Vet Pathol 35: 461-478, 1998.

30. Kaczanowski S: Apoptosis: its origin, history, maintenance and the medical implications for cancer and aging. Phys Biol 13: 3 , 2016.

31. Wong RS: Apoptosis in cancer: From pathogenesis to treatment. J Exp Clin Cancer Res 30: 87, 2011.

32. Arumugam A and Razis AF: Apoptosis as a mechanism of the cancer chemopreventive activity of glucosinolates: A Review. Asian Pac J Cancer Prev 19: 1439-1448, 2018.

33. Pistritto G, Trisciuoglio D, Ceci C, Garufi A and D'Orazi G: Apoptosis as anticancer mechanism: function and dysfunction of its modulators and targeted therapeutic strategies. Aging (Albany NY) 8: 603-619, 2016.

34. Liu T, Wu Z, He Y, Xiao Y and Xia C: Single and dual target inhibitors based on Bcl-2: Promising anti-tumor agents for cancer therapy. Eur J Med Chem 201: 112446, 2020

35. Kalpage HA, Wan J, Morse PT,Zurek MP, Turner AA, Khobeir A, Yazdi N, Hakim L, Liu J, Vaishnav A, et al: Cytochrome $c$ phosphorylation: Control of mitochondrial electron transport chain flux and apoptosis. Int J Biochem Cell Biol 121: 105704, 2020.

36. Sun J and Nan G: The mitogen-activated protein kinase (MAPK) signaling pathway as a discovery target in stroke. J Mol Neurosci 59: 90-98, 2016.

37. Raman M, Chen W and Cobb MH: Differential regulation and properties of MAPKs. Oncogene 26: 3100-3112, 2007.

38. Fang JY and Richardson BC: The MAPK signalling pathways and colorectal cancer. Lancet Oncol 6: 322-327, 2005.

39. Berlowska J, Dudkiewicz M, Kregiel D, Czyzowska A and Witonska I: Cell lysis induced by membrane-damaging detergent saponins from Quillaja saponaria. Enzyme Microb Technol 75-76: 44-48, 2015.

40. Rao AV and Sung MK: Saponins as anticarcinogens. J Nutr 125 (Suppl 3): 717S-724S, 1995 .

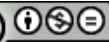

This work is licensed under a Creative Commons Attribution-NonCommercial-NoDerivatives 4.0 International (CC BY-NC-ND 4.0) License. 